\title{
BLOOD LOSS DURING EMERGENCY CAESAREAN SECTION OF PLACENTA PREVIA IS MORE AS COMPARED TO ELECTIVE CAESAREAN SECTION
}

\author{
SARDAR MUHAMMAD ALFAREED ZAFAR, MEHVISH ILYAS, SAIMA SAEED USMANI, \\ MARYAM JAVED, RIZWANA TARIQ \\ Department of Obstetrics \& Gynaecology, Postgraduate Medical Institutel Ameer-ud-Din Medical Collegel \\ Lahore General Hospital, Lahore
}

\begin{abstract}
Background: Placenta Previa is one of the major obstetric complication. It is a serious condition that may lead to severe morbidity and mortality. The risk of cesarean and blood loss, particularly, in emergency cesarean section.

Objective: To compare the mean blood loss and need for blood or blood products with emergency versus elective cesarean section in females with placenta previa.

Methods: The design of this study was cohort. It was conducted at Department of Obstetrics \& Gynaecology, Lahore General Hospital, Lahore. Duration of the study was 3 months (April to June 2020). Sample size of 70 patients were enrolled in the study through Non-Probability, Consecutive Sampling. Patients of age 20-40 years, presented > 24 weeks of pregnancy, with diagnosis of placenta previa were included. Then females were booked and were followed-up in OPD till delivery. Emergency cesarean section was done if active labor and bleeding started while elective cesarean was done on given date for delivery. Intraoperative blood loss and need for blood or blood components transfusion was noted. Data was recorded on proforma and analyzed by using SPSS version 22.

Results: The mean age of females in emergency group was $30.80 \pm 4.36$ years and mean age of females in elective group was $31.06 \pm 3.76$ years. The mean gestational age of females at delivery in emergency group was $35.74 \pm 2.89$ weeks and in elective group was37.54 \pm 0.70 weeks. The average blood loss during emergency caesarean section was $1471.43 \pm$ $891.65 \mathrm{ml}$ while during elective cesarean section, average blood loss was $1042.86 \pm 402.41 \mathrm{ml}(\mathrm{p}<0.05)$. In emergency caesarean group, 7 (20\%) did not require blood transfusion while $28(80 \%)$ required blood transfusion. In elective caesarean group, $21(60 \%)$ did not require blood transfusion while $14(40 \%)$ required blood transfusion $(\mathrm{p}<0.05)$. Conclusion: Though this study, we found significantly higher blood loss and need for blood transfusion in emergency caesarean section as compared to elective caesarean sections for placenta previa.
\end{abstract}

Key words: Blood loss, emergency caesarean section, placenta Previa, blood transfusion, fresh frozen plasma, elective caesarean section

How to cite this article: Zafar SMAF, Ilyas M, Usmani SS, Javed M, Tariq R. Blood loss during emergency caesarean section of placenta previa is more as compared to elective caesarean section. Pak Postgrad Med J 2020;31(3):146-150

This is an Open Access article distributed under the terms of the Creative Commons Attribution License (http://creativecommons.org/licenses/by/3.0), which permits unrestricted use, distribution, and reproduction in any medium, provided the original work is properly cited.

DOI: https://doi.org/10.51642/ppmj.v31i03.393

Correspondence to: Mehvish Ilyas,

Department of Obstetrics \& Gynaecology,

Postgraduate Medical Institute/ Ameer-ud-Din

Medical College/Lahore General Hospital, Lahore

Email:aimaan85@hotmail.com

\section{INTRODUCTION}

Placenta previa is an obstetrical complication, in which the tissues of placenta lies abnormally in the uterus, very near to the cervical ostium from internal side. ${ }^{1}$ Previous uterine surgeries or trauma is the most probable risk factor of placenta previa. ${ }^{2}$ About $10 \%$ pregnant females develop placenta previa. ${ }^{3}$ Several other risk factors also involved as the risk for placenta previa like previous cesarean sections, increased number of conceptions, advanced maternal age, abortion, dilatation and curettage or myomectomy. ${ }^{4}$ The chances of placenta previa are high in scarred uterus. The females with placenta previa along with history of previous scars are also at high risk of developing placenta accreta. ${ }^{5}$

The presence of injury or scar in the uterus due to previous cesarean section with either anterior or posterior placenta previa covering the previous uterine scar increases the risk of placenta Previa. The important or worth of early detection of placenta Previa during antenatal period is that it allows to determine multidisciplinary preparation and management protocols in order to minimalize the possible complications for both mother and neonate including mortality. ${ }^{6-8}$ 
Primarily, the placenta previa is located in lower segment of the uterus, it is the area which is continuously disposes the uterine bleeding. This may be due to the development and growth of new blood vessels and owing to weak contractibility of this uterine area. The complication, assessed by destruction of tissue, newly developed vessels and vascular incursion of the adjacent tissues, necessitates the multi-disciplinary management protocol. When respective procedures are done, an appropriate plan to challenge the surgical complications allows better regulation of intraoperative bleeding and evades avoidable hysterectomies. ${ }^{9}$

During or after delivery of pregnancies complicated with placenta previa, the blood loss is typically a major problem, which can lead to severe obstetrical morbidity and even maternal mortality. ${ }^{10}$ Careful approximation of the intra-operative blood loss during a cesarean section is significantly important in terms of reduced intraoperative complications and evasion of hazards associated with the avoidable blood transfusions. ${ }^{11,12}$

The aim of the study is to compare the mean blood loss and need for blood or blood products with emergency versus elective cesarean section in females with placenta previa. It has been observed that operative blood loss is high in females with placenta previa as compared to caesarean sections done in normal pregnancies. Mostly, females with placenta previa undergo caesarean deliveries in emergency conditions. So, there is a need to determine whether the blood loss is significantly higher in emergency caesarean sections or in elective cases. So, we want to conduct this study to attain the local evidence and implement the screening of pregnant females with placenta previa to plan improved management protocols in order to avoid unnecessary emergency caesarean deliveries.

\section{METHODS}

The design of this study was cohort. It was conducted at Department of Obstetrics \& Gynaecology, Lahore General Hospital, Lahore. Duration of the study was 3 months (April to June 2020). Data of 70 females is calculated with $95 \%$ confidence level, $7 \%$ margin of error and taking expected percentage of placenta Previa i.e. $10 \%{ }^{3}$ in pregnant females. Sampling Technique was Non-Probability, Consecutive Sampling. Patients of age 20-40 years, presented $>24$ weeks of pregnancy, with diagnosis of placenta previa were included. Placenta previa was diagnosed by using transabdominal ultrasound. Female were those females who had chronic or gestational hypertension, preeclampsia, renal dysfunction, bleeding disorders, multiple fetus, anemia or antepartum hemorrhage were excluded from the study. 70 females fulfilled the selection criteria were enrolled in this study from OPD. Informed consent was obtained and demographic information including age, BMI, gestational age, parity and number of previous cesarean sections were recorded. Then females were booked and were followed-up in OPD. Females was asked to present in labor room when active labor started. Female were underwent emergency cesarean section if active labor and bleeding started otherwise females were given date for delivery through cesarean section. Females were divided in two groups i.e. emergency and elective cesarean section and 35 in each group were assessed for blood loss during surgery and requirement of blood transfusion or fresh frozen plasma. Intraoperative blood loss was measured by using cotton swabs and tray. Females were managed as per standard protocols. Data was recorded on proforma and analyzed by using SPSS version 22. Mean blood loss was compared in both groups by using independent samples t-test and blood transfusion and fresh frozen plasma by using chi-square test. P-value $\leq 0.05$ was kept as significant.

\section{RESULTS}

The mean age of females in emergency group was 30.80 \pm 4.36 years and mean age of females in elective group was $31.06 \pm 3.76$ years. The mean gestational age of females at delivery in emergency group was $35.74 \pm 2.89$ weeks and in elective group was37.54 \pm 0.70 weeks. There were $0(0 \%)$ primigravida, 24 (68.6\%) multigravida (1-4) and $11(31.4 \%)$ grand multigravida ( $\geq 5)$ among emergency cases while 2 (5.7\%) primigravida, $26(74.3 \%)$ multigravida (1-4) and 7 $(20.0 \%)$ grand multigravida $(\geq 5)$ among elective group. There were $0(0 \%)$ primiparous, $25(71.4 \%)$ multipara $(1-3)$ and $10(28.6 \%)$ grand multiparous $(\geq 4)$ among emergency cases while $2(5.7 \%)$ primiparous, 27 $(77.1 \%)$ multiparous (1-3) and 6 (17.1\%) grand multiparous $(\geq 4)$ among elective group. In emergency group, $16(45.7 \%)$ had previous no cesarean section, 15 (42.9\%) had previous 1-2 cesarean section and 4 (11.4\%) had previous 3-4 cesarean section. In elective group, 28 (80\%) had previous no cesarean section, 4 (11.4\%) had previous $1-2$ cesarean section and $3(8.6 \%)$ had previous 3-4 cesarean section. There were significantly higher number of previous cesarean sections in emergency cases $(\mathrm{p}<0.05)$. Table 1

The mean blood loss during caesarean section was observed as $1257.14 \pm 719.82 \mathrm{ml}$. Mostly females had $800 \mathrm{ml}$ to $1500 \mathrm{ml}$ blood loss. Fig 1

The average blood loss during emergency caesarean section was $1471.43 \pm 891.65 \mathrm{ml}$ while during elective cesarean section, average blood loss was $1042.86 \pm$ $402.41 \mathrm{ml}$. The difference was significant $(\mathrm{p}<0.05)$. In emergency caesarean group, 7 (20\%) did not require blood transfusion while $28(80 \%)$ required blood transfusion, out of which $22(62.9 \%)$ females had 1-3 blood pints while $6(17.1 \%)$ females required $>3$ blood pints. In elective caesarean group, 21 (60\%) did not require blood transfusion while $14(40 \%)$ required blood transfusion, out of which $12(34.3 \%)$ females had 1-3 blood pints while $2(5.7 \%)$ females required $>3$ blood pints. The difference was significant $(\mathrm{p}<0.05)$. In emergency caesarean group, $22(62.9 \%)$ did not require fresh frozen plasma transfusion while $13(37.1 \%)$ required blood transfusion, out of which $11(31.4 \%)$ 
females had 1-3 blood pints while $2(5.7 \%)$ females required $>3$ blood pints.

Fig 1: Histogram showing distribution of blood loss $(\mathrm{ml})$

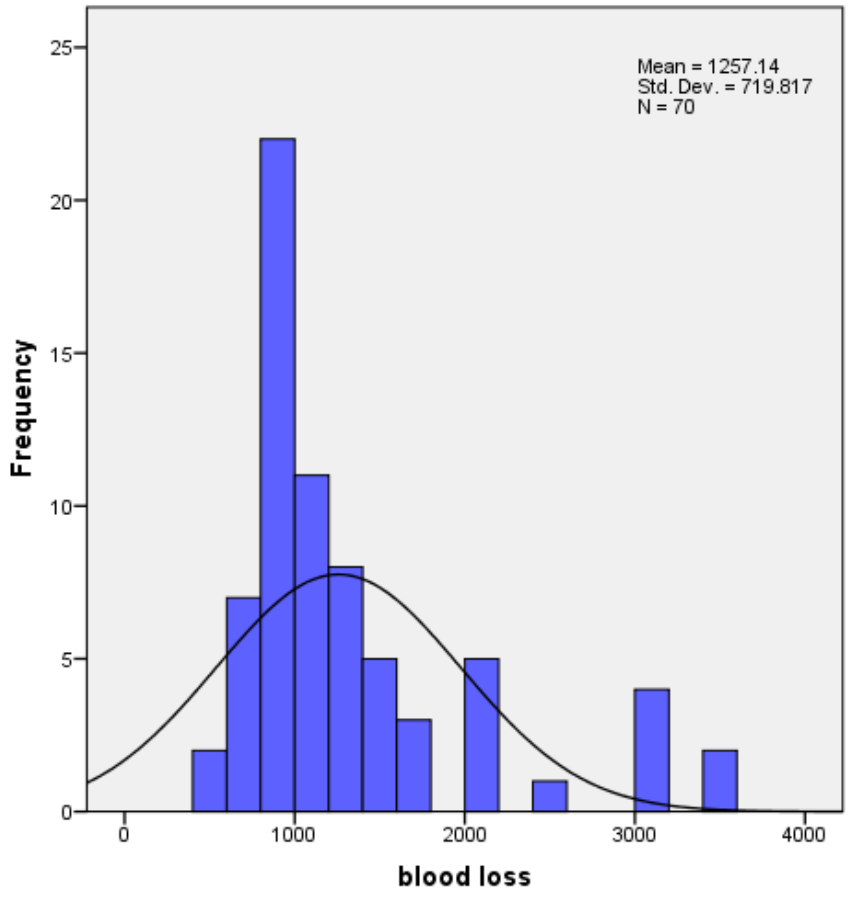

In elective caesarean group, $30(85.7 \%)$ did not require fresh frozen plasma transfusion while $5(14.3 \%)$ required blood transfusion, out of which $12(34.3 \%)$ females had $1-3$ blood pints while no $(0 \%)$ females required $>3$ blood pints. The difference was insignificant $(\mathrm{p}>0.05)$. Table 2

Table 1: Demographics of patients

\begin{tabular}{lcc}
\hline & \multicolumn{2}{c}{ Group } \\
\cline { 2 - 3 } & Emergency & Elective \\
\hline \multicolumn{1}{c}{$\mathrm{n}$} & 35 & 35 \\
Age (yeas) & $30.80 \pm 4.36$ & $31.06 \pm 3.76$ \\
Gestational age (weeks) & $35.74 \pm 2.89$ & $37.54 \pm 0.70$ \\
BMI (kg/m²) & $28.20 \pm 3.61$ & $27.97 \pm 4.51$ \\
Gravida & & \\
Primigravida & $0(0 \%)$ & $2(5.7 \%)$ \\
Multigravida & $24(68.6 \%)$ & $26(74.3 \%)$ \\
Grand multigravida & $11(31.4 \%)$ & $7(20.0 \%)$ \\
Parity & & \\
Primiparous & $0(0 \%)$ & $2(5.7 \%)$ \\
Parity 1-3 & $25(71.4 \%)$ & $27(77.1 \%)$ \\
Parity 4-7 & $10(28.6 \%)$ & $6(17.1 \%)$ \\
Number of Previous caesareans & \\
0 & $16(45.7 \%)$ & $28(80.0 \%)$ \\
$1-2$ & $15(42.9 \%)$ & $4(11.4 \%)$ \\
$3-4$ & $4(11.4 \%)$ & $3(8.6 \%)$ \\
\hline
\end{tabular}

Table 2: Comparison of blood loss and need for blood / fresh frozen plasma transfusions

\begin{tabular}{lccr}
\hline & & Group & \multirow{2}{*}{ P - value } \\
\cline { 2 - 3 } & Emergency $(\mathrm{n}=35)$ & Elective $(\mathrm{n}=35)$ & 0.013 \\
Intraoperative Blood loss $(\mathrm{ml})$ & $1471.43 \pm 891.65$ & $1042.86 \pm 402.41$ & \\
Need for Blood transfusion & $7(20 \%)$ & $21(60 \%)$ & 0.003 \\
$\quad$ None & $22(62.9 \%)$ & $12(34.3 \%)$ & $2(5.7 \%)$ \\
$1-3$ & $6(17.1 \%)$ & & \\
$>3$ & & $30(85.7 \%)$ & 0.065 \\
Need for Fresh frozen plasma & $22(62.9 \%)$ & $5(14.3 \%)$ & $0(0 \%)$ \\
$\quad$ None & $11(31.4 \%)$ & $2(5.7 \%)$ & \\
$1-3$ & & & \\
$>3$ & &
\end{tabular}

$*=\mathrm{p}$-value $<0.05$ (Significant)

\section{DISCUSSION}

Pregnant females with previous uterine scars and central placenta previa have to face serious complications including abundant post-partum haemorrhage and placental adhesions post-delivery. Certain attention must be given to the females with previous uterine scars in next pregnancy to avoid the development of placenta previa and to decrease the hazards to such deliveries, so promoting prognosis estimation. ${ }^{2}$

Placenta previa is the rare type of impaired plantation of placenta where it grows in lower side of the uterine cavity and covers partially or completely the internal cervical os. The average frequency of placenta previa at the time of delivery $0.5 \%$ of live births (1/200 births). Implantation in lower side is noted in $28 \%$ pregnancies before 24 weeks, while $18 \%$ after 24 weeks, but only in
$3 \%$ at term. ${ }^{13}, 14$ The incidence of placenta previa in scarred uterus is significantly high $(1.2 \%)$ as compared to overall incidence $(0.6 \%){ }^{15}$

As in placenta previa, when the placenta lies completely over the cervical os, it might be essential to cross that placenta to deliver the fetus. This is a type of maneuver that normally causes an excessive bleeding. ${ }^{16}$ Then, placental detachment may help to produce additional bleeding, because of poor contractility of lower segment of the uterine and due to its increased blood circulation. If the hemorrhage is not management quickly, the process may worsen the condition and end in coagulopathy or other severe complications. ${ }^{17}$ Therefore, the rationale method in such cases is to prevent the bleeding at first and then done an easy and precise control of excessive bleeding. In such complicated cases, 
access to upper vaginal part and lower segment of the uterine is essential to control the bleeding. ${ }^{18}$

In our study, the mean gestational age of females at delivery in emergency group was $35.74 \pm 2.89$ weeks and in elective group was37.54 \pm 0.70 weeks. The average blood loss during emergency caesarean section was $1471.43 \pm 891.65 \mathrm{ml}$ while during elective cesarean section, average blood loss was $1042.86 \pm 402.41 \mathrm{ml}$ $(p<0.05)$. This showed significantly more blood loss with emergency caesarean sections. In emergency caesarean group, 28 (80\%) females required blood transfusion. In elective caesarean group, $14(40 \%)$ females required blood transfusion $(\mathrm{p}<0.05)$.

In one trial, the rate of excessive bleeding was less in females who underwent cesarean section under elective conditions i.e. $2.1 \%$ as compared to the females who underwent cesarean delivery in emergency circumstances. The diverse pattern of risk for hemorrhage in after cesarean sections must be determined before planning the accessible obstetrical competency for surgery. ${ }^{19}$ In another study, the intraoperative excessive bleeding or hemorrhage was defined as the blood loss $>1000 \mathrm{ml},{ }^{20}$ while in three more trial, intra- \& post-operative hemorrhage was defined as the blood loss was $>1,500 \mathrm{ml}^{21-23}$

The frequency of hemorrhage in elective versus emergency cesarean sections was reported as $6.8 \%$ in elective cesareans versus $9.0 \%$ in emergency cesareans, despite no differences in risk profile between the studied populations (rate of emergency operations, abruptio placental, placenta previa, obesity, previous cesarean sections and skills of surgeons). ${ }^{20}$ Two Norwegian trial applying >1,500 $\mathrm{ml}$ as the definition of excessive blood loss, had less rate ${ }^{21}$ but the American study reported the higher prevalence. ${ }^{22,23}$

\section{CONCLUSION}

Though this study, we found significantly higher blood loss and need for blood transfusion in emergency caesarean section as compared to elective caesarean sections for placenta previa. Now, we have got the evidence and now we recommend the females for regular screening of females with placenta previa during antenatal period in order to detect and control the complications of placenta previa that may lead to emergency caesarean sections to prevent excessive blood loss.

\section{LIMITATIONS}

Study was carried out on seventy females; thirty-five in each group. However, authenticity of results can improve with larger sample size and more findings can be elaborated. Only very few parameters like blood loss and need for blood transfusion were assessed. Also, females were not followed-up prolonged after delivery to assess further complications of placenta Previa and blood loss or transfusions as well as females were not further assessed for adverse reactions of transfusions.

\section{SUGGESTIONS / RECOMMENDATIONS}

Further studies can be done on larger sample size to obtain more authentic results. Multi-centric studies can also be done to obtain more authentic results. More parameters including haemoglobin or haematocrit changes, effect on neonates and blood transfusion related complications or reactions can also be assessed in future studies.

\section{CONFLICT OF INTEREST / DISCLOSURE}

No conflict of interest to be declared by any author involved in the research.

\section{ETHICAL APPROVAL}

The study was approved from Institutional Review Board of Postgraduate Medical Institute/Ameer ud Din Medical College/Lahore General Hospital, Lahore, Pakistan,

\section{REFERENCES}

1. Yang T, Li N, Qiao C, Liu C. Development of a Novel Nomogram for Predicting Placenta Accreta in Patients With Scarred Uterus: A Retrospective Cohort Study. Front Med (Lausanne) 2019;6:289.

2. Zheng J, Liu S, Xing J. Prognosis and related risk factors of patients with scarred uterus complicated with central placenta previa. Ginekologia polska 2019;90 (4):185-188.

3. Majeed T, Waheed F, Mahmood Z, Saba K, Mahmood $\mathrm{H}$, Bukhari MH. Frequency of placenta previa in previously scarred and non scarred uterus. Pak J Med Sci 2015 Mar-Apr;31(2):360-363.

4. Bashir A, Jadoon HN, Abbasi AU. Frequency of placenta previa in women with history of previous caesarean and normal vaginal deliveries. Journal of Ayub Medical College, Abbottabad : JAMC 2012 JulDec;24(3-4):151-153.

5. Price FV, Resnik E, Heller KA, Christopherson WA. Placenta previa percreta involving the urinary bladder: a report of two cases and review of the literature. Obstetrics and gynecology 1991 Sep;78(3 Pt 2):508-511.

6. MacDorman M, Declercq E, Menacker F. Recent trends and patterns in cesarean and vaginal birth after cesarean (VBAC) deliveries in the United States. Clinics in perinatology 2011 Jun;38(2):179-192.

7. Todman D. A history of caesarean section: from ancient world to the modern era. Australian and New Zealand Journal of Obstetrics and Gynaecology 2007;47(5):357-361.

8. Lurie $\mathrm{S}$. The changing motives of cesarean section: from the ancient world to the twenty-first century. Archives of gynecology and obstetrics 2005;271 (4):281-285.

9. Palacios-Jaraquemada JM. Caesarean section in cases of placenta praevia and accreta. Best Practice \& Research Clinical Obstetrics \& Gynaecology 2013;27(2):221-232. 
10. Ashraf Aly H, Ramadani HM. Assessment of blood loss during cesarean section under general anesthesia and epidural analgesia using different methods. AJAIC 2006;9(1):25-34.

11. Vimala N, Mittal S, Kumar S. Sublingual misoprostol versus oxytocin infusion to reduce blood loss at cesarean section. International Journal of Gynecology \& Obstetrics 2006;92(2):106-110.

12. el Sharkwy IAE. Carbetocin versus sublingual misoprostol plus oxytocin infusion for prevention of postpartum hemorrhage at cesarean section in patients with risk factors: a randomized, open trail study. Archives of gynecology and obstetrics 2013;288(6):1231-1236.

13. Hasan S, Imtiaz F, Ali A, Sultana A. Feto-Maternal Outcome of Placenta Praevia after Previous Cesarean Section in a Tertiary Care Hospital. Epidemiology 2014;2014.

14. Nasreen F. Incidence, Causes and outcome of placenta previa. J Postgrad Med Inst 2011;17(1).

15. Mathuriya G, Lokhande P. Comparative study of obstetric outcome between scarred and unscarred uterus in placenta previa cases. Indian $\mathbf{J}$ Clin Pract 2013;24(6):568-571.

16. Xiaojing J, Ying W, ahmad Khan I. Clinical analysis of 322 cases of placenta previa. Journal of Medical Colleges of PLA 2009;24(6):366-369.

17. Palacios-Jaraquemada J, Fiorillo A. Conservative approach in heavy postpartum hemorrhage associated with coagulopathy. Acta obstetricia et gynecologica Scandinavica 2010;89(9):1222-1225.
18. PALACIOS-JARAQUEMADA JM. Efficacy of surgical techniques to control obstetric hemorrhage: analysis of 539 cases. Acta obstetricia et gynecologica Scandinavica 2011;90(9):1036-1042.

19. Kolås T, Øian P, Skjeldestad FE. Risks for peroperative excessive blood loss in cesarean delivery. Acta obstetricia et gynecologica scandinavica 2010;89 (5):658-663.

20. Bergholt T, Stenderup JK, Vedsted-Jakobsen A, Helm $\mathrm{P}$, Lenstrup C. Intraoperative surgical complication during caesarean section: An observational study of the incidence and risk factors. Obstetrical \& gynecological survey 2003;58(10):649-650.

21. Eggebo T, Gjessing L. Haemorrhage after caesarean delivery. Tidsskr Nor LÆgeforen 2000;24:2864-2866.

22. Naef 3rd R, Chauhan SP, Chevalier SP, Roberts WE, Meydrech EF, Morrison JC. Prediction of hemorrhage at cesarean delivery. Obstetrics and gynecology 1994;83(6):923-926.

23. Al-Zirqi I, Vangen S, Forsen L, Stray-Pedersen B. Prevalence and risk factors of severe obstetric haemorrhage. BJOG: An International Journal of Obstetrics \& Gynaecology 2008;115(10):1265-1272.
AUTHOURS CONTRIBUTIONS
SMAFZ: Literature Review, Supervision
MI, SSU: Manuscript Writing
MJ, RT: Data Collection 